\title{
Can ePortfolios Scaffold Competency-based Workplace Learning in Low-income Countries? Lessons Learnt from a Qualitative Pilot Study in Midwifery Education in Rwanda
}

\author{
Mieke Embo ${ }^{1,2 *}$ Hilde De Grave ${ }^{1}$ Séverine Van Der Stighelen ${ }^{1}$ Martin Valcke ${ }^{2}$ Olive \\ Tengera $^{3}$ Alice Muhayimana ${ }^{3}$ Josephine Murekezi ${ }^{4}$ Jean Pierre Ndayisenga $^{3,5}$ \\ Donatilla Mukamana ${ }^{3}$ \\ ${ }^{1}$ Midwifery department, Artevelde University of Applied Sciences, Ghent, Belgium. \\ ${ }^{2}$ Department of Educational Studies, Faculty of Psychology and Educational Sciences, University of Ghent, Belgium. \\ ${ }^{3}$ School of Nursing and Midwifery, University of Rwanda, Kigali, Rwanda. \\ ${ }^{4}$ King Faisal Hospital, Kigali, Rwanda. \\ ${ }^{5}$ Arthur Labatt Family School of Nursing, Western University, London, Ontario, Canada. \\ *Corresponding author. Email: mieke.embo@arteveldehs.be
}

\begin{abstract}
Background: Rwanda and other low-income countries face a critical shortage of competent midwives. This capacity problem threatens the attainment of the Sustainable Development Goals by 2030. Competency-based midwifery education (CBME) holds the best promise of developing competencies and improving patient outcomes. However, challenges arise when developing and implementing competency-based frameworks and ePortfolio tools in low-income countries.

Aim: This study explored midwifery students', mentors' and supervisors' perceptions about the applicability of an ePortfolio designed on an evidence-based Continuous Workplace Learning Competency Framework.

Methods: Using a qualitative descriptive design, in depth-individual interviews were carried out with four midwifery students, two midwife mentors from selected hospitals and two midwife supervisors from a midwifery teaching institution. All interviews were audio-taped, transcribed verbatim and thematically analysed using NVIVO12 software Findings: All participants preferred ePortfolio over paper-based portfolio because of the continuous online accessibility of information. This accessibility encouraged collaboration between stakeholders, facilitated self-monitoring of performance, enhanced IT competency, reduced time and costs of handling portfolios and improved, in some cases, feedback. Nevertheless, the success of implementing a competency-based ePortfolio was strongly dependent on the extent to which essential conditions were met: devices, internet connectivity, time and training. The ePortfolio was not used in its full potential because of lack of knowledge of different categories of the Competency Framework.

Conclusions: The results of this pilot study suggest that ePortfolios are the future to support workplace learning. An important lesson is that low-income countries must first implement the principles of CBME in clinical education followed by the design of ePortfolios according to evidence-based competency frameworks.
\end{abstract}

Keywords: Midwifery, Competency-based education, Clinical competence, Workplace, Online portfolio, Rwanda.

\section{INTRODUCTION}

Rwanda and other low-income countries face a critical shortage of competent midwives, leading to substantial neonatal and maternal morbidity and mortality [1,2]. This capacity problem threatens the attainment of the Sustainable Development Goals (SDG's) by 2030 [3]. Competency-based education $(\mathrm{CBE})$ has been recognized internationally as a system of education and training that holds the best promise of 
improving learner and patient outcomes [4,5]. One challenge has been finding tools to teach and assess competence in the workplace. Many educators and researchers believe that the use of electronic portfolios (ePortfolios) can help to fill this need. Unfortunately, the implementation of ePortfolios is often ineffective and the impact on learning is limited [6]. This study elaborates on the results of a pilot project, exploring the application of a competency-based ePortfolio in support of workplace learning during midwifery education in Rwanda.

Since the beginning of the 21 st century (often referred to as the digital age), the extent and impact of competencies and competency development have been increasing constantly [7]. CBE has been promoted as a means to educate healthcare professionals, including nurses and midwives. In CBE, success is measured solely by achieving outcomes within a flexible timeline, determined individually by the learner [5]. Implementing $\mathrm{CBE}$ in an authentic healthcare workplace is complex and requires the implementation of structural frameworks [8]. A wide variety of $\mathrm{CBE}$ frameworks have been proposed to conceptualize $\mathrm{CBE}$ in clinical practice. Researchers in Belgium have developed a framework to use in workplace learning environments which focuses on student competency development in the clinical setting $[9,10]$. Within the framework the components of workplace learning were divided into 6 categories: 1) CBE and competency framework, 2) workplace stakeholders, 3) learning, assessment and supervision processes (6 steps), 4) learning and assessment instrument, 5) programmatic learning and assessment (holistic and longitudinal view on learning) and 6) essential workplace learning conditions [11]. This framework was designed in the context of undergraduate midwifery education, and cited by authors in the context of other professions such as Nursing [8], Dietetics [12], Athletic training [13], Construction workers [14], Physiotherapy [15], Radiography [16], Medicine [17,18], IT and Management [19]. The authors referred to the value of one or more categories outside the framework. In this study the research explored the effect of the original framework on CBE in the workplace, in lowincome countries.

The progressive shift to $\mathrm{CBE}$ challenged educators to find competency-based tools that encourage reflective practice, put a structure around competency development and fit within the complex workplace reality. Over the past decades, a variety of portfolios have been introduced as learning and assessment tools in undergraduate medical education [20,21]. Portfolios have appeared in various shapes and forms. Moreover, they were used in a multitude of different settings and for different purposes [22]. While paper-based portfolios (PBP) are still used, ePortfolios are coming into increasing use [23,24]. They have been introduced into many higher education curricula to help students link theory, practice and personal experiences, to encourage reflection, to develop and demonstrate competence, and as an instrument for assessment and evaluation [25]. The popularity of ePortfolios is increasing because they offer several advantages over traditional PBP. They are easy to complete, access and modify, they allow for easier storage of all pertinent information [23,24,26], they have the ability to include multimedia and overviews of personal development [22], users of ePortfolios add more personal content to their portfolios and spend more time on them [24,27]. In addition, ePortfolios have also been found to motivate students more than PBP [20,28]. The electronic format also allows for built-in mechanisms that facilitate learning, such as reminders to ensure that users have properly completed the sections of the tool and have engaged in in-depth reflection on their experience and the impact on their learning [24]. This is not to say that the process of supporting self-directed learning (SDL) is radically different between the two. The process of doing so with ePortfolios is likely more efficient [22].

Despite the increasing evidence that ePortfolios can be successful to underpin learning, certain issues frequently overshadow the potential benefits of ePortfolio use in a higher education setting across many disciplines, particularly in health sciences [24]. Implementation difficulties related to technology, expertise, staff attitudes, miscommunication or a mismatch between the intention of curriculum designers and the students' actual experience. Users' perspectives of ePortfolios are not widely-canvassed in the literature. In particular, there is little evidence of whether students themselves feel ePortfolio use helps them to develop personally and professionally, and whether they feel ePortfolios are effective in assessing their learning and competence [25].

During a 2-year funded innovation project, a competency-based ePortfolio, based on an evidencebased Continuous Workplace Learning Competency Framework [10], was piloted at two clinical teaching hospitals in Kigali (Rwanda). Recently, the authors published the results of the project, describing perceptions on the use of the clinical teaching portfolio (PBP and ePortfolio) of midwifery students, mentors (hospital) and supervisors (university) [29]. This paper focuses on the perceptions of the ePortfolio users, especially on the suitability of the framework and the ePortfolio tool. The following research questions were addressed:

Was the ePortfolio design, based on the 'Continuous Workplace Learning Competency Framework' applicable in the context of midwifery workplace learning in Rwanda? 
What were the perceived benefits, challenges and recommendations of a competency-based clinical workplace learning ePortfolio for midwifery students, mentors and supervisors?

\section{MeTHODS}

\subsection{Context}

This VLIR/UOS project was conducted between the University of Rwanda (UR) and the Artevelde University of Applied Sciences, Ghent, Belgium (AUS). This project supported the UR in developing a competencyand evidence-based learning framework in the clinical workplace with the aim to enhance the quality of clinical education in Rwanda. The AUS has a long tradition in competency-based midwifery education. Between 2008 and 2015, Embo's Continuous Workplace Learning Competency Framework was developed, using a paperand-pencil format. In 2016, this format was transformed into an online Medbook $($, a commercial ePortfolio platform by the company Imengine (Belgium) who specialize in developing ePortfolios in healthcare education.

Evidence showed the positive effects of the different categories of the framework: 1) the CBE structure promoted a focus on realistic outcomes; 2) using established competencies promoted continuity between formal learning and workplace expectations, and provided a common language between stakeholders; 3) the visualization of the workplace processes in six steps facilitated continuous competency development. These six steps were: competency selection, formulating learning goals, self-monitoring of performance, selfassessment of competency development, summative assessment of individual competencies and summative assessment of global professional competence; 4) a competency-based instrument was key in facilitating CBE; 5) promotion of a longitudinal programmatic approach stimulated continuous lifelong competency development; and 6) essential conditions must be fulfilled before implementing a competency based framework in practice. Experiences in the context of clinical education in midwifery in Ghent were received positively and were applicable to other midwifery programs in Flanders [30,31] and other health care professions (oral health, speech pathology, occupational therapy, and others). However, whether this would also apply to other countries - especially low-income countries like Rwanda - was never investigated. Therefore, this study was set up to explore whether the Framework and ePortfolio would fit midwifery workplace learning reality in Rwanda.
During the first year of the project (2018), the research team decided that the Continuous Workplace Learning Competency Framework from Embo et al. [10], including the ePortfolio Medbook $\odot$ could be used in the context of Rwanda. In the second year, the study was piloted at two clinical teaching hospitals in Kigali. In April 2019, a workshop was organised in order to train students, mentors (workplace) and supervisors (university lecturers) to use Medbook@.The pilot started in May 2019 and ended in October 2019.

\subsection{Study design}

A descriptive qualitative design was used to explore the perceptions of midwifery students, mentors and supervisors on the use of ePortfolio.

\subsection{Study population and sample}

The study was conducted with midwifery undergraduate students, mentors and supervisors who had been in clinical placement at the two selected clinical teaching hospitals, who had used PBP that was implemented in 2014 and who were interested in participating in the ePortfolio pilot project. The purposive sampling strategy [32] was used to select participants who could provide rich information on their perceptions of the use of both portfolio formats. Participants sent a letter information introducing the study and inviting them to participate. They were subsequently contacted by the research team members. Participants needed to fulfil the following inclusion criteria: be a midwifery student, have a supervisor and/or mentor allocated at two selected clinical teaching hospitals, be familiar with the existing PBP, have been introduced to the ePortfolio and be willing to be part of the study. Midwifery students, mentors, and supervisors who were not enrolled in Medbook@ and who had not been exposed to existing PBP and ePortfolio were excluded [29].

Initially, 12 students, 4 mentors and 4 supervisors were selected to participate in the project. In an earlier publication [29] perceptions from all the selected participants were reported. In this study, only ePortfolio users participated. Between the period of May to October 2019 , a total of 8 participants including 4 undergraduate midwifery students, 2 mentors from 2 selected clinical teaching hospitals and 2 supervisors from the midwifery department from UR enrolled in the Medbook $\odot$ platform and were involved in this study. 


\subsection{Data collection}

Data for this study was collected at the end of the clinical placement where participants shared their perceptions on the use of ePortfolio. Using a semistructured interview guide, in-depth individual interviews of 45 to 60 minutes were carried out with midwifery students, mentors and supervisors. Participants signed a consent form immediately prior to the start of the interview. All correspondence and interviews were carried out in English. The interviews were conducted, recorded and transcribed verbatim by the researchers from UR. The study was approved by the College of Medicine and Health Sciences (CMHS) Institutional Review Board (IRB), No 125/CMHS IRB/2019.

\subsection{Data analysis}

Inductive thematic analysis determined the process of data analysis. A six-step thematic analysis as outlined by Braun and Clarke (2006) [33] was undertaken, which included becoming familiar with the data through reading all the long answer responses, generating initial codes by working in a systematic manner throughout the data set and undertaking discussions between the researchers, searching for themes which involved grouping initial codes into meaningful themes relevant to the research question, reviewing the themes which occurred through assessing themes in relation to codes and the overall data set, defining and naming themes and producing the results paragraph [34]. Data was analysed using the NVIVO 12 software.

\section{RESULTS}

We present the results according to the 6 categories of Embo's Continuous Workplace Learning Competency Framework [10].

\subsection{Competency-based education and competency framework}

The competency framework of the midwifery department of AUS was translated and used in this pilot project. The analysis revealed that the principles of CBE were unknown. The word 'competency' was only mentioned by one mentor. She said that it was time to learn more about competences (R7, mentor).

\subsection{Workplace stakeholders}

One of the most important perceived benefits of ePortfolio was the continuous online accessibility which had a positive effect on the collaboration between the stakeholders. This meant that everyone (all stakeholders involved in workplace learning) had access to the same information anytime (during and after working days; before and after graduation) and everywhere (clinical placement, university, home,...). This 'sharing capability' of the ePortfolio resulted in 1) an enhanced interaction within the clinical workplace, 2) a stronger collaboration between the mentor and the supervisor, and 3 ) a strengthened relationship between the workplace and the university.

All stakeholders agreed on the positive effect of this ePortfolio platform on the interaction between students, midwives, mentors and supervisors. Students had to take the initiative to start the interaction by inviting mentors and teachers to share the platform after they received a link from the company. Students and their supervisors were positive about the effect on students' learning.

"When we start using it, the company sends an email and that email contains a link, then you sign up. Before I couldn't think that there is a platform where you can fill your everyday works. The format is good you can fill your daily objectives and I liked how the platform is being used by many people sharing what you are doing $(R 2$, student)."

Furthermore, ePortfolios were valuable in reducing the theory/practice gap and in strengthening the relationship between the university and the clinical placement. Supervisors could read how students had implemented skills in the clinical placement and compare this with the way it was taught in class. One mentor perceived this as a kind of observation or follow up from the university which was perceived as supporting deeper learning:

"Another it's the way hospitals are involved in clinical or students mentorship to make sure that everything the students do is credible, it means for the PBP the student can give things which are not credible for example which they got from Google but for ePortfolio it's not easy to cheat (R6, mentor)".

\subsection{Learning, Assessment and Supervision processes}

The third category of the framework was the visualisation of the learning, assessment and supervision processes at the workplace in a 6-step model. Notwithstanding that the Medbook $\odot$ portfolio was designed according the 6 steps, the analysis revealed that only one of the participants used all the steps or functionalities. The opposite was documented in the following quotes.

"Yes! I have used all windows available in this system with the help of the supervisor and the system. I tried to 
use all the windows....setting objectives, evaluation and so on (R3, student)".

“Uh, at this time, I didn't manage to use all parts. The part that was easy was to give feedback for students on clinical learning goals and reflection but for the part of assessment, still now, I still have challenge to log in and to give assessment (R5, supervisor).

\section{Step 1: competency selection}

When students added objectives or reflections, they had to match them with the competencies that were entered in the portfolio. As mentioned before, only one mentor used the word competency. This mentor was also aware of the functionality of connecting objectives with competencies.

\section{Step 2: Formulating objectives}

Four participants perceived a positive effect on formulating 'objectives' while the majority connected them to daily reflections (step 3) instead of formulating objectives for the full learning period at the workplace, as was intended in the framework.

"Another benefit, it is for the one using it you know that after inserting your objectives, reflective journal and your daily activities you will get the feedback easily so that is another benefit (R3, student)."

Another problem was that respondents did not understand the purpose of formulating personal objectives in order to adapt learning to individual learning needs. The difference between personal objectives and standardised competency-based criteria was unclear.

"Yeah it was a big challenge to supervise all those students but they have the same objectives it was not that very difficult to supervise them ( $R 4$, supervisor)."

\section{Step 3: Self-monitoring performance}

This third step was well established and all stakeholders perceived positive effects of the ePortfolio on students' self-monitoring competencies and mentors' and supervisors' competency in facilitating learning. Students were familiar with the self-regulating learning cycle of action, reflection, submission and feedback on daily performances. Students found it easy to send their work directly to the supervisor: "I have my phone and the internet I can send my work directly to the supervisor or the lecturer. ...." (R2, student). " One mentor told us that this ePortfolio enhanced staff involvement because midwives felt motivated to give feedback on daily observations. Students had the opportunity to write feedback in the ePortfolio and the mentor and supervisor could read this and add feedback. The fact that ePortfolio created a connection between people facilitated this step 'I think it's good for students' learning as there is a connection between each people which helps students to learn ... we share experiences and many parts give feedback (R5, supervisor)."

Although self-monitoring performance is aimed at monitoring daily performances over time, participants focussed on daily activities and quick learning instead of documenting progress during the full internship. Nevertheless, several advantages of the ePortfolio on the supervising progress were detected. Mentors and supervisors could monitor students' activities and talk about students' learning without being in the same place. They could combine ideas and knowledge which helped them to stay updated of any change that might occur in the clinical placement. This shared involvement in students' learning resulted, in some cases, in better/ meaningful and immediate feedback (R6, mentor). This also meant that the ePortfolio offered an opportunity to follow students' gradual progress rather than to wait until the end of the internship to see the progress (R5, supervisor). One supervisor pointed out the importance of instructing students to continuously document their learning in ePortfolio: "For the student, firstly, I recommend them to post progressively their record instead of waiting at the end of the clinical (R5, supervisor)". Another advantage was that the ePortfolio gave mentors and supervisors the opportunity to follow the self-monitoring process of different students at the same time. "On my side I have seen that it's very good and interesting because it helps us to monitor those students even now I can see how many students I have mentored and the feedbacks I have given and I can save their portfolio (R7, mentor)".

\section{Step 4: Reflection and feedback on competency development}

The fourth step, self-assessing competency development, was not used. Students did not enter reflections on progress and mentors or supervisors did not give feedback on progress. Only one supervisor used the word 'progress' but related this to step 3, daily reflections on activities.

\section{Step 5: Summative assessment of individual competencies}

Only a few comments were given on how the ePortfolio assist in summative assessment. One mentor said that she was aware that assessment could be done automatically as it was regulated in the machine (R7, mentor) but two supervisors told us that they did not see assessments and that they needed training before implementing this: "No it was not easy. I think when this 
continues we need like I can say trainings to train the students, mentors and supervisors (R4, supervisor)."

\section{Step 6: Assessment of global professional competence (summative score)}

This final step was not used in this pilot project. Time was too short to train supervisors and faculty to implement this step during the pilot project.

\subsection{Workplace learning and assessment instrument}

\subsubsection{Preference}

All respondents preferred ePortfolio above the PBP for different reasons. They expressed happiness and gratitude for having received the opportunity to participate in this pilot project. A promising finding was that almost all respondents recommended the implementation of the ePortfolio early in the program and to expand its use to other students, professions and institutions.

"I can recommend to the university of Rwanda to make the system available everywhere in the clinical placement as it facilitates the work and keeps you active. So I recommend its usage which is good for all the students (R3, student)."

"I wish this ePortfolio can be introduced in all nursing schools not only in the U.R because every student should be on the same level despite the schools they went on (R6, mentor)."

"If the resources are enough I can recommend the use of the e portfolio because it's easy (R4, supervisor)."

Participants reported similar problems and pitfalls with the functionality of both PBP and ePortfolio. According to them, both formats are aimed at improving the learning process by setting objectives, making reflections and archiving them in the logbook. As mentioned before, the focus was on reporting daily activities (step 3). One mentor viewed the ePortfolio as an electronic version of the PBP by saying "the two have the same topic and content (R7)”. Another supervisor perceived this similarity as the reason why it was not so difficult to supervise students with the ePortfolio (R4). Interestingly, one student said that there were also negative similarities such as the difficulty to receive effective feedback: "The experience is much more like using the PBP we didn't get the feedback (R2, student)". Importantly, one mentor detected a pitfall of an ePortfolio and emphasised the importance of keeping face-to-face feedback dialogues, even when using ePortfolios (R7).

\subsubsection{Connection with the digital world}

Students were happy with this ePortfolio because it was user-friendly and helped them to move into the digital world, to enhance their IT competencies and to stay updated. Also, mentors and supervisors were positive, though they recognized that using ePortfolio was easier for students than for mentors and supervisors. A supervisor (R5) identified differences in attitudes and skills between students and supervisors. She said that students were young and eager to post, that they were more active and had more time. She documented this by saying "I can say that for the part of students they are more excited than us". Nevertheless, she was also happy to be part of the portfolio team and developed IT competencies:

"I have been using e-portfolio from last month ago I was happy to be part of the portfolio team as the supervisor but at the beginning I couldn't get a clear understand of what it was about but progressively I sort it out. At the beginning even log in was a challenge for me. I logged in and I couldn't find the path where to get in my part and to get student part, but as time comes I get the login and I found that it was easy, despite to the connection and time. So, even I have identified advantage of using it after knowing how to enter and how to save a student record (R5, supervisor)".

\subsubsection{Effect on time management and learning speed (timely feedback)}

The three most frequent counted words in NVIVO were Portfolio, feedback and time. That is the reason why we combine time and feedback here and also later in the conditions (paragraph 3.6).

Respondents preferred the ePortfolio because of its time- effectiveness. They told us how the ePortfolio took less time to complete and no time to print, send, store or search documents as was the case with PBP: "So, what I did every day? When I finished my daily activities I used to sit down and type on without even using 15 minutes. Then after writing I sent directly so that the feedback came immediately but for those like PBP, it took just time for you to go and bring hard papers and take time to write then, it took another time to submit and to get the feedback, it was late (R1, student)".

Students appreciated that they could complete their portfolio wherever they wanted: "Another difference is on accessibility. The way of accessing the PBP, it was not easy. This ePortfolio, you can access your portfolio like at job, driving cars,... wherever! But for paper based you need to go where you kept the papers to access them (RI, student)"; "I mean it can be used anywhere like at home or the clinical placement (R2, student)". 
As documented in the above quote, time was regularly linked to the timing of receiving feedback and the effect on learning. Some students perceived that feedback was easier and provided directly which resulted in fast(er) learning.

" I experienced many things which are good and among those experiences I saw that through that Eportfolio...Time management because It takes little time to type what I have done and I share it directly and get the feedback without taking much time. ... Quick learning here... I think when I am given feedback immediately it means I take decision accordingly and quickly which improve my learning speed... meaning I will do correct things in a short time compared to paper based where It will require long time to get feedback to correct where they commented (Rl, student).

Also, the mentors perceived advantages of the online tool with their time management. They could give feedback without meeting the students e.g. when they had no time to go in the field. They also perceived a benefit to the quality of feedback "And for the mentor it helps to give the feedback with many evidence as you had time to read and discuss about the case after reading ( $R 7$, mentor)".

\subsubsection{Cost-effective}

Respondents appreciated that ePortfolios were cheaper than PBP because of the lower cost of the internet and no printing costs. Lower internet cost related to the huge number of documents that had to be completed and sent to the supervisor when using the PBP. For an ePortfolio, only the internet connectivity had to be paid.

"Imagine like when you have the portfolio of 15 pages in one clinical placement and another 15 and another.... imagine how many pages you will have in 3years! But for ePortfolio they are many but well placed (R1, student)."

"This portfolio, it costs a lower price because for example if you the mb's of 100Rwf we may do more with it and achieve the objectives and get the feedback with only 100Rwf (R3, student)."

\subsubsection{Effect on safe and lifelong storage}

According to some respondents, one of the main benefits of an ePortfolio is the safe online storage of students' personal information during and after graduation. Information is available from anywhere, it can't be lost and logbooks can't be misplaced. Stored information is valuable as a memory support for the learner: "You know .... you have to wait for two weeks for the teacher to present what you have done so the papers can be misplaced, imagine where the papers of the fifty students are kept at the xxx hospital. But you know for the e portfolio it's safe it's like a personal book (R7, mentor)."

Another advantage is that information was available after graduation. "Yeah that's where again ePortfolio is more important, it means when you open data you'll see everything that you have done. Even the feedbacks from the supervisor. Even after the graduation you can still access it (R2, student)."

\subsection{Programmatic learning and assessment}

The fifth category of the framework was not relevant in this pilot project because students used the ePortfolio only during one internship.

\subsection{Essential workplace learning conditions}

The success of implementing a competency-based ePortfolio is strongly dependent on what essential conditions were met and to what extent. Participants were asked to identify the major barriers and challenges in using the ePortfolio, and to provide recommendations for further improvement. The analysis revealed 3 themes: 1) devices and internet; 2) time and feedback; and 3) training and motivation.

\subsubsection{Devices and Internet}

It is apparent that implementing ePortfolios in clinical practice requires devices (PC, laptop, phone) and internet for all stakeholders involved in workplace learning. A supervisor said, "mentoring is easy when they have materials, training and facilities ( $R 4$, supervisor)". Without these, learners can't submit reflections and mentors/supervisors can't give feedback.

All but one participant addressed the shortage of devices. A real barrier is that not all students have a computer. They overcome this barrier by using their phone. Almost all students have a phone but typing on phones is harder because of lower typing speed and a less clear screen. When students have no device, they share them, or they use a device from the hospital. Also in hospitals, there is a lack of computers. Mentors from both hospitals told us that they overcame this by sharing available computers in the hospital (R7, mentor). Perceptions about devices for supervisors were mixed. One student told us that supervisors used to have computers: "When they come to do the supervision they use their PC to give feedback but there are some who give feedback from their homes (R1, student)". One supervisor told us that they are challenged by internet connectivity and the lack of laptops as the students do ( $\mathrm{R} 4$, supervisor). We found different recommendations 
from supervisors, some recommended that program managers should allow supervisors to use the schools' portable computer (laptop) wherever they go to supervise students and to give them the opportunity to have internet connection (R5, supervisor). Only one supervisor preferred a computer at the workplace because she perceived it challenging "to go everywhere with her laptop (R5, supervisor)."

A related barrier to the lack of devices was that internet was neither available everywhere nor all the time ("it is sometimes on or off"). Most students had no internet access (R2, student), which is the reason why they used the hospital's internet connection. One student told us that they address this problematic internet connection in two ways "... like we buy internet data and connect or we arrange time like in the extras time to use the hospital wifi... (R1, student)." The latter did not solve all problems as a student told us "The internet.... We ask the password to connect but also that is a challenge. When the numbers of connection increases, the internet speed decreases (R1, student)". One mentor added that connection during the night was more difficult than during the day (R7, mentor). It was recommended by students and supervisors to provide at least one room with computers and internet at the university.

\subsubsection{Time and Feedback}

Mentors and supervisors reported a lack of time to guide students due to high workload and the difficulty in combining supervising students with PBP and ePortfolio. Notwithstanding the high number of students and patients and the low staff rates, the analysis revealed that staff, mentors and supervisors were motivated to supervise students. In reality that meant supervising students in their free time: "Yes I work during the day but as you know the day is overloaded so I use my free time after work (R6, mentor)"; “... if it's possible they can use the day offs so they can come and help the students (R7, mentor)" and "...as the time is limited I try to use my time when I am home or in the weekends to go through the portfolio and try to give the feedbacks to students (R4, supervisor)."

High workload also had an impact on students. They had to write their reflections in their free time but no students reported that they perceived this as problematic. Students had totally different perceptions on receiving feedback. The majority of students told us how difficult it was to get informative feedback on daily performance. Feedback was related to observed performance. Students were instructed to write oral feedback from mentors in their ePortfolio but they had different experiences of the feedback they received. One student told us that he did not receive feedback on performances, instead he received "to do's about the procedure (R1, student)".
This was different from another student who received immediate feedback during the caring process (R3, student). Students were more positive about the feedback they received from supervisors than from staff and mentors, but the problem was that supervisors didn't observe them during daily practice.

\subsubsection{Training and motivation}

Respondents emphasized that students, mentors and supervisors must be trained and, sometimes, motivated to use ePortfolio appropriately. A qualitative training must focus on access and usability of the tool, on applying the underlying pedagogical CBE-principles, and on respecting essential underlying conditions. A supervisor suggested to start the training with the students because they are younger and have more time to search. Welltrained students can train their mentors and supervisors and stimulate peer learning in the team.

"For the student, it was easy to access to put the objective of learning to logged daily activities as you have said they are young, they have time to search. So for us, for me, I get troubled to log in and to find the record. So what was the challenge for me? It was to understand first and second was time as I have other students also to follow up to get feedback on clinical site but for now I think for the part of giving feedback it is okay and enough for me (R5, supervisor)."

It was also recommended to adapt training to the different levels of knowledge and experience of the ePortfolio users. Finally, mentors and supervisors asked guidance and support from the department and program manager. They recommended to be given the opportunity to learn more about ePortfolios and to be followed and supported by them.

\section{DISCUSSION}

This paper discusses the findings of a pilot project which explored students', mentors' and supervisors' experiences of using a competency-based ePortfolio to support learning, assessment and supervision during an internship at two clinical teaching hospitals in Rwanda. Two research questions were addressed in order to answer the overarching question "Can ePortfolios scaffold competency-based workplace learning in lowincome countries and what lessons can we learn from this pilot study?

The first research question was to explore suitability of Embo's Continuous Workplace Learning Framework [10] in the context of midwifery education in Rwanda. The results revealed that the Framework was not used to its full potential, as was the case with almost all the authors who cited the framework [8,12-19]. We discuss 
some findings based on the 6 categories of the framework: 1) CBE, 2) Stakeholders, 3) Processes, 4) Instrument, 5) Conditions, and 6) Programmatic view.

An important first finding was that the concepts of CBE, competency frameworks and competencies were rather unknown. The literature describes the complexity of implementing CBE in authentic healthcare workplaces [8] but emphasizes the value of CBE in that it makes explicit what educators expect from their learners in a language that the professionals in the domain understand naturally [5]. If $\mathrm{CBE}$ is to be the new paradigm for midwifery education, we must collectively identify how the barriers to successful implementation in Rwanda and other low-income countries can be overcome. A recent study in medical education identifies how regulatory bodies can support and advance worldwide efforts of furthering its implementation [35].

Second, the participants were very positive about the effect of an ePortfolio on the collaboration between the stakeholders [24]. The continuous online accessibility of learner's information stimulated interaction and active participation and strengthened the relationship between the workplace and the university. Online platforms make it possible that everyone has access to the same information anytime and anywhere; this advantage of an ePortfolio over PBP may convince educators, university managers and government to invest in ePortfolios as was also stated in the policy documents $[3,36]$.

The third category described the workplace learning, assessment and supervision processes that structures a random internship in 6 steps. The results revealed that only the third step (self-monitoring performances) was well established, possibly because this was also instructed in the PBP. This study confirmed midwifery AUS students' perceptions [37]. Immediate reflection on performance enabled a willingness to change and motivated students to seek feedback to improve their practice, whereas general reflection on competencies was seen more as a compulsory exercise offering less learning [24]. The reflective learning models in the literature illustrate the recognised need for healthcare professionals in undergraduate education to provide structure to the students' reflective process. Multiple reflective learning models have been designed to support the development of student reflection to improve the quality of care provided in practice. Although some literature advocates that students need support in learning this skill, there is limited evidence about what teaching practices are the most effective [38-40]. Another important finding was that the fifth step, assessment of competencies, was difficult to implement. The data suggested that this was mainly because the assessment process was unknown, rather than evaluating the value of the tool on assessment. More research is needed to explore how ePortfolio assessment can be used as an alternative form to classic testing in which a student's progress is evaluated over a period of time and would thus meet the needs for authentic and competency-based evaluation [7,21]. It is recommended to conduct further longitudinal research on the implementation of the fifth and sixth steps that were designed to support competency-based assessment in practice.

The fourth and fifth steps of the Framework give an answer on the second research question that is "What were participants' perceived benefits, challenges and recommendations of a competency-based clinical workplace learning ePortfolio?" The results indicated that this ePortfolio tool (category 4), developed in the context of midwifery education in Flanders (Belgium), was well received by students, mentors and supervisors in midwifery education in Kigali (Rwanda). All participants preferred the ePortfolio above the PBP one and recommended to roll it out to other students, other professions, and other institutions. Respondents acknowledged some difficulties associated with the ePortfolio. Nonetheless, they cited numerous advantages to the use, and typically, believed that ePortfolios had an overall positive effect on their workplace learning. One of the major benefits was the connection with the digital world and on developing IT-competencies. Mentors and supervisors recognized that students were younger and eager to use the ePortfolio. A lot of comments were made about a lack of functional ICT facilities to accommodate efficient portfolio use. ICT facilities need to function well and be readily available for students who develop SelfDirected Learning (SDL) skills with an ePortfolio. Beckers et al. (2016) described the negative influence of lack of technological competence on the development of SDL skills with an ePortfolio [21]. Other benefits were that this ePortfolio was easy to complete, to access and to modify, and it allowed for easier storage of all pertinent information [24]. Respondents also considered a positive effect on time management and the quality and quantity of the feedback given. Nevertheless, we learnt also that time and feedback were still problematic issues that urgently needed to be addressed when implementing an ePortfolio. Although respondents were highly motivated to use the ePortfolio, they indicated lack of time due to high workload. Consequently, they had to complete the ePortfolio in the evenings, during weekends or holidays. Completing and reviewing portfolios is widely viewed as time consuming and it is already known that time demands of a portfolio should be reasonable [24]. One way to do this is by scheduling protected time for portfolio use [22]. Another way is to further explore valuable technological innovations that can be implemented in the tool such as built-in mechanisms that facilitate learning, reminders to ensure engagement in indepth learning [41]. Students also addressed the difficulty 
in receiving informative feedback on daily activities due to unobserved performance. This brings us to the most important recommendation, that ePortfolio users must be trained appropriately in the use of an ePortfolio. An interesting suggestion was to train students first and to encourage them to train their mentors and supervisors. The available empirical research indicates that the use of ePortfolios is influenced by a number of factors 1) the institute, 2) the curriculum, 3) the learning process, 4) the user and 5) the portfolio itself [22]. The design of the ePortfolio can facilitate or hinder its successful application [42]. Situations in which all conditions are met still seem rare. As we found in this study, there appears to be plenty of room for improvement and the full potential of ePortfolios has not yet been reached [43]. This is the case for many countries. Further research could be embedded in the African Union continental Science, Technology and Innovation Strategy (STISA2024), aimed at ensuring that science, technology and innovation contribute to the sustainable development efforts of Africa [44].

The sixth and final step of the framework, Programmatic learning and assessment, couldn't be explored because this pilot project had a duration of one internship, the reason why the sixth step wasn't implemented. Nevertheless, the authors suggest taking into account current literature when designing a Rwandaspecific ePortfolio because this programmatic view will change the assessment culture towards an approach which emphasises assessment for learning $[45,46]$.

\section{LIMITATIONS}

The major limitation of this study was the small sample size. The targeted sample of students, mentors, and supervisors was limited because participation was voluntary, and the project resources were limited. Despite the small sample size, the results in this study are valuable because the essential voice of key stakeholders was considered, something that is scarce in current ePortfolio literature [43]. This study has identified the perceptions of an ePortfolio from the perspective of the end user - in this case, the student, the mentor at the hospital and the supervisor from the university. A second limitation was that the duration of this pilot was short because of limited internship weeks for final year students. It is likely that a longitudinal approach would better capture the variations in - and development of participants' perceptions, experiences, and attitudes regarding the portfolio-based learning approach as it unfolds across the program.

\section{CONCLUSION}

The results of this pilot study suggest that, although workplace learning ePortfolios can successfully scaffold competency-based midwifery education in low-income countries, the design of this ePortfolio was not used to its full potential. All participants preferred an ePortfolio above PBP thanks to the continuous online accessibility of information which encouraged collaboration between the stakeholders, facilitated self-monitoring of performances, enhanced IT competencies, reduced time and cost to handle portfolios and improved feedback, in some cases. This pilot study indicates that the success of implementing a competency-based ePortfolio is strongly dependent on the extent to which essential conditions are met. The analysis in this study revealed three conditions that needed improvement: 1) devices and internet connectivity; 2) time and feedback; 3) training and motivation. A major challenge for Rwanda, as for many other countries, is to implement the principles of competency-based education in their curricula and to design ePortfolios that are built on evidence-based competency frameworks and current ePortfolio technology. The continued testing and refining of ePortfolio design and implementation is required to help realise the overarching aim of midwifery education, that is to develop midwives who are competent to deliver quality care that meets a woman's individual needs.

\section{AUTHORS' CONTRIBUTIONS}

All authors were involved in the design of this research, participated in manuscript development, and critically revised the manuscript for its intellectual content. This ePortfolio project was funded by a VLIR/UOS grant. The software company Imengine provided free Medbook@ accounts and guidance during the project.

\section{ACKNOWLEDGMENTS}

The authors thank Sofie Van Ostaeyen and Vasiliki Andreou for their feedback and Tracy Embo for her final language check.

\section{REFERENCES}

[1] World Health Organization. (2016). The Work of WHO Rwanda in 2014-2015: Biennium Supporting Health Services Delivery for Universal Health Coverage in Rwanda.

[2] Uwizeye, G., Mukamana, D., Relf, M., Rosa, W., Kim, M. J., Uwimana, P., ... \& Moreland, P. (2018). Building nursing and midwifery capacity through Rwanda's human resources for health program. Journal of Transcultural Nursing, 29(2), 192-201. 
[3] Johnston, R. B. (2016). Arsenic and the 2030 Agenda for sustainable development. Arsenic Research and Global Sustainability As, 12-14.

[4] Gruppen, L., Frank, J. R., Lockyer, J., Ross, S., Bould, M. D., Harris, P., .. \& ICBME Collaborators. (2017). Toward a research agenda for competency-based medical education. Medical teacher, 39(6), 623-630.

[5] van der Vleuten, C. P. (2015). Competency-based education is beneficial for professional development. Perspectives on Medical Education, 4(6), 323-325.

[6] Van Schaik, S., Plant, J., \& O'sullivan, P. (2013). Promoting self-directed learning through portfolios in undergraduate medical education: the mentors' perspective. Medical teacher, 35(2), 139-144.

[7] Rezgui, K., Mhiri, H., \& Ghédira, K. (2017). Ontology-based e-Portfolio modeling for supporting lifelong competency assessment and development. Procedia computer science, 112, 397406.

[8] Baumgartner, R., Häckter Ståhl, C., Manninen, K., \& Rydholm Hedman, A. (2017). Assessment of nursing students in clinical practice. An intervention study of a modified process. Journal of Nursing education and practice, 7(11), 111-122.

[9] Flott, E. A. (2017). Facilitating Student Learning in the Acute Care Setting: Nursing Faculty Perspectives (Doctoral dissertation, College of Saint Mary).

[10] Embo, M., Driessen, E., Valcke, M., \& van der Vleuten, C. P. (2015). Integrating learning assessment and supervision in a competency framework for clinical workplace education. Nurse education today, 35(2), 341-346.

[11] Abdelmarouf, H. (2017). Mohieldein Outcomebased approach to medical education towards academic programmes accreditation: A review article. JPMA Jornal of Pakistan medical association.

[12] Palermo, C., Gibson, S. J., Dart, J., Whelan, K., \& Hay, M. (2017). Programmatic assessment of competence in dietetics: a new frontier. Journal of the Academy of Nutrition and Dietetics, 117(2), 175-179.

[13] Mace, K. L., \& Bacon, C. E. W. (2018). Athletic training educators' knowledge and confidence about competency-based education. Athletic Training Education Journal, 13(4), 302-308.
[14] Utomo, H. B., Harto, S. P., \& Jaedun, A. (2019). ASSESSMENT MODEL OF COMPETENCE CERTIFICATION FOR CONSTRUCTION WORKERS. International Journal of Control and Automation, 12(7), 37-48.

[15] Sturt, R., Burge, A. T., Harding, P., \& Sayer, J. (2018). Physiotherapists' perceptions of workplace competency: a mixed-methods observational study. Australian Health Review, 42(4), 461-468.

[16] Kilgour, A. J. (2018). Radiography assessment for practice: A critical practice enquiry (Doctoral dissertation, Charles Sturt University, Wagga Wagga, Australia).

[17] Favreau, M. A., Tewksbury, L., Lupi, C., Cutrer, W. B., Jokela, J. A., \& Yarris, L. M. (2017). AAMC Core Entrustable Professional Activities for Entering Residency Faculty Development Concept Group. Constructing a shared mental model for faculty development for the core entrustable professional activities for entering residency. Acad Med, 92(6), 759-764.

[18] Dudek, N., Gofton, W., Rekman, J., \& McDougall, A. (2019). Faculty and resident perspectives on using entrustment anchors for workplace-based assessment. Journal of graduate medical education, 11(3), 287.

[19] Rabogadi, T. A. (2017). Strategies information and communication technology managers use to build employee competencies.

[20] Driessen, E., Van Tartwijk, J., Van Der Vleuten, C., \& Wass, V. (2007). Portfolios in medical education: why do they meet with mixed success? A systematic review. Medical education, 41(12), 1224-1233.

[21] Buckley, S., Coleman, J., \& Khan, K. (2010). Best evidence on the educational effects of undergraduate portfolios. The clinical teacher, 7(3), 187-191.

[22] Beckers, J., Dolmans, D., \& Van Merriënboer, J. (2016). e-Portfolios enhancing students' selfdirected learning: A systematic review of influencing factors. Australasian Journal of Educational Technology, 32(2).

[23] Tochel, C., Haig, A., Hesketh, A., Cadzow, A., Beggs, K., Colthart, I., \& Peacock, H. (2009). The effectiveness of portfolios for post-graduate assessment and education: BEME Guide No 12. Medical teacher, 31(4), 299-318.

[24] Foucault, M. L., Vachon, B., Thomas, A., Rochette, A., \& Giguère, C. É. (2018). Utilisation of an electronic portfolio to engage rehabilitation professionals in continuing professional 
development: results of a provincial survey. Disability and rehabilitation, 40(13), 15911599.

[25] Birks, M., Hartin, P., Woods, C., Emmanuel, E., \& Hitchins, M. (2016). Students' perceptions of the use of eportfolios in nursing and midwifery education. Nurse education in practice, 18, 46-51.

[26] Gordon, J. A., \& Campbell, C. M. (2013). The role of ePortfolios in supporting continuing professional development in practice. Medical Teacher, 35(4), 287-294.

[27] Van Tartwijk, J., \& Driessen, E. W. (2009). Portfolios for assessment and learning: AMEE Guide no. 45. Medical teacher, 31(9), 790-801.

[28] Driessen, E. W., Muijtjens, A. M., Van Tartwijk, J., \& Van Der Vleuten, C. P. (2007). Web-or paperbased portfolios: is there a difference?. Medical education, 41(11), 1067-1073.

[29] Mukamana, D., Embo, M., Tengera, O., Muhayimana, A., Murekezi, J., DeGrave, H., ... \& Valcke, M. (2020). Perceptions of midwifery students, mentors, and supervisors on the use of clinical teaching portfolio in Rwanda. Journal of Nursing Education and Practice, 10(10), 52-60.

[30] Embo, M., \& Valcke, M. (2016). Workplace learning in midwifery education in Flanders (Belgium). Midwifery, 33, 24-27.

[31] Embo, M. (2017). A competency-based midwifery e-workplace learning portfolio: concept, theory and pedagogy. Global Journal of Health Science \& Nursing, 1, 109.

[32] Sandelowski, M. (1999). Time and qualitative research. Research in Nursing \& Health, 22(1), 7987.

[33] Braun, V., \& Clarke, V. (2006). Using thematic analysis in psychology. Qualitative research in psychology, 3(2), 77-101.

[34] Maguire, M., \& Delahunt, B. (2017). Doing a thematic analysis: A practical, step-by-step guide for learning and teaching scholars. All Ireland Journal of Higher Education, 9(3).

[35] Nousiainen, M., Scheele, F., Hamstra, S. J., \& Caverzagie, K. (2020). What can regulatory bodies do to help implement competency-based medical education?. Medical Teacher, 42(12), 1369-1373.

[36] Agyepong, I. A., Sewankambo, N., Binagwaho, A., Coll-Seck, A. M., Corrah, T., Ezeh, A., ... \& Piot, P. (2017). The path to longer and healthier lives for all Africans by 2030: the Lancet Commission on the future of health in sub-Saharan Africa. The Lancet, 390(10114), 2803-2859.

[37] Embo, M. P. C., Driessen, E., Valcke, M., \& Van Der Vleuten, C. P. (2014). Scaffolding reflective learning in clinical practice: a comparison of two types of reflective activities. Medical teacher, 36(7), 602-607.

[38] Austin, D., Gilkison, A., \& Clemons, J. (2020). Turning reflection into learning: a practice development tool for midwifery students. Reflective Practice, 21(3), 301-315.

[39] Schmutz, J. B., \& Eppich, W. J. (2017). Promoting learning and patient care through shared reflection: a conceptual framework for team reflexivity in health care. Academic Medicine,92(11), 15551563 .

[40] Larsen, D. P., London, D. A., \& Emke, A. R. (2016). Using reflection to influence practice: student perceptions of daily reflection in clinical education. Perspectives on medical education, 5(5), 285-291.

[41] Vachon, B., Foucault, M. L., Giguère, C. É., Rochette, A., Thomas, A., \& Morel, M. (2018). Factors influencing acceptability and perceived impacts of a mandatory ePortfolio implemented by an occupational therapy regulatory organization. Journal of Continuing Education in the Health Professions, 38(1), 25-31.

[42] Pearson, D. J., \& Heywood, P. (2004). Portfolio use in general practice vocational training: a survey of GP registrars. Medical education, 38(1), 87-95.

[43] Watson, C. E., Kuh, G. D., Rhodes, T., Light, T. P., \& Chen, H. L. (2016). ePortfolios-The eleventh high impact practice. International Journal of ePortfolio, 6(2), 65-69.

[44] UNION, A. (2019). Five-Year Science, Technology and Innovation Plan of Action 2019-2024.

[45] Harrison, C. J., Könings, K. D., Schuwirth, L. W., Wass, V., \& van der Vleuten, C. P. (2017). Changing the culture of assessment: the dominance of the summative assessment paradigm. BMC medical education, 17(1), 1-14.

[46] Torre, D. M., Schuwirth, L. W. T., \& Van der Vleuten, C. P. M. (2020). Theoretical considerations on programmatic assessment. Medical teacher, 42(2), 213-220. 